\title{
Yaşlı Bakım Hizmetleri
}

\author{
Elderly Care Services
}

\section{Asu GÜRER ${ }^{1}$ (D), Fidan KÜDÜR ÇIRPAN ${ }^{1}$ (D), Nazan ATALAN ÖZLEN ${ }^{1}$}

öz

Günümüzde hızla gelişen bilim ve teknoloji tıpta önemli ilerlemelere neden olmaktadır. Erken tanı ve tedavi yöntemleri gelişmiş, hastalıklara bağlı ölümler azalmış, doğumda beklenen yaşam süresi artmış, bireylerin yaşam standardı yükselmiştir. 20 . yüzyılın ikinci yarısından itibaren dünya nüfusunun yaşlanma eğiliminin arttığ 1 gözlenmektedir. Bu sonuç sadece demografik bir durum değildir. Yaşlı nüfusun artması ile birlikte yaşlılarla ilgili politikaların üretilmesi ve sosyal düzenlemelerin yapılması gerekmektedir. Demografik verilere bakıldığında ülkemizde de yaşlı nüfusunun hızla arttığını görmekteyiz. Dolayısıyla bu durum yaşl1lığın ülkemiz için de üzerinde düşünülmesi gereken bir durum haline gelmeye başladığını bize göstermektedir.

$\mathrm{Bu}$ makalede, ülke örnekleri ile dünyadaki yaşlı bakım hizmetlerinin özelliklerine değinilmiştir. Türkiye'deki yaşlı bakım hizmetleri hakkında bilgi verilerek konunun önemine dikkat çekmeye ve bu konuda farkındalık yaratmaya çalışılmıştır.

Anahtar Kelimeler: Yaşlılık, yaşlı sağlığı, yaşlı bakım hizmetleri.
Asu GÜRER(凶), Fidan KÜDÜR ÇIRPAN, Nazan ATALAN ÖZLEN

${ }^{\prime}$ Marmara Üniversitesi Sağllk Hizmetleri Meslek Yüksekokulu, Anestezi Programi, İstanbul

e-posta:asu.gurer@marmara.edu.tr

\section{ABSTRACT}

Today, science and technology are developing rapidly and enormous progress is being made. With this progress, early diagnosis and treatment methods have improved, deaths due to diseases have decreased, life expectancy at birth has increased, and the standard of living has increased. As a result, the aging population has been increasing since the second half of the 20th century. This situation does not only have a demographic problem, the production of the policies concerning the elderly, it is necessary to make the necessary arrangements. When we look at the demographic data, we see that the elderly population is increasing rapidly in our country. Therefore, this case shows us that we started to become an aging country's situation needs to be considered for.

In this article, the characteristics of the country examples and the elderly care services in the world are mentioned. They are given information about elderly care services in Turkey. It is tried to draw attention to the importance of the subject and to raise awareness about this issue.

Keywords: Elderly, elderly health, elderly care services.

\section{GİRIŞ}

Dünya Sağlık Örgütü (DSÖ) 1963 yılında yaşlıların sağlık sorunları konusunda düzenlediği toplantıda yaşl1lıkla ilgili şu sınıflamayı yapmıştır:

- 45-59 yaş arası orta yaş,

- 60-74 yaş arası yaşl11ık,

- 75-89 yaş arası ileri yaşlılık,

- 90 ve üstü ise ihtiyarlık kategorisine alınmıştır.

DSÖ 1980’lerde yaşlılığı “65 yaşından büyük olup bireyin çevreye uyum sağlayabilme yeteneğini kaybetmesi" olarak tanımlamış ve şu şekilde revizyona gitmiştir.

- 65-74 yaş arası genç yaşlılık,

- 75-84 yaş arası orta yaşlılık,

- $\quad 85$ ve üstü ise ileri yaşlılık. 
Bilim ve teknolojideki gelişmelerin sonucunda doğan sanayileşme ve kentleşme ile birlikte, yeni açılımlar meydana gelmiş, ilerlemelere paralel olarak insan ömrünün uzaması sağlanmıştır. Özellikle batılı ülkelerde refah düzeyinin artması ile tıpta yeni gelişmeler hız kazanmıştır. Kırsal bölgelerden kentsel alanlara doğru göç oranları artmış, doğum oranlarında düşüşler gözlenmiş, ölüm hızı azalmış ve yaşlı nüfusta önemli bir artış olmuştur. Yaşlı nüfustaki artış eğiliminin gelecek yıllarda da devam etmesi öngörülmektedir.

2017 yılında dünya nüfusunun \%8,9'unu yaşlı nüfus oluşturmaktaydı. En yüksek yaşlı nüfus oranına sahip ilk üç ülke sirasiyla \%32,2 ile Monako, \%27,9 ile Japonya ve $\% 22,1$ ile Almanya oldu. Türkiye bu siralamada 167 ülke arasında 66. sırada yer aldı (1). Dünyada yaşlı nüfusun 2050 yılında 1.97 milyar olması beklenmektedir. Avrupa bölgesi, toplam nüfusundaki \%20'lik yaşlı oranıyla, dünyanın yaşlı nüfusu en fazla bölgesi olarak kabul edilir ve gelecek 20 yıl içinde yaşlı nüfusunun hızla artarak \%29'a çıkacağ 1 düşünülmektedir.

Ülkemizde de yaşlı nüfus hızlı bir şekilde artmaktadır. 65 ve daha yukarı yaş olarak ifade edilen yaşlı nüfus, 2013 yılında 5 milyon 891 bin 694 kişi iken son beş yılda \%17 artarak 2017 yılında 6 milyon 895 bin 385 kişi oldu. Yaşlı nüfusun toplam nüfus içindeki oranı ise 2013 yılında $\% 7,7$ iken, 2017 yılında \%8,5'e yükseldi. Yaşlı nüfusun \%44'ünü erkek nüfus, \%56'sını kadın nüfus oluşturdu. Nüfus projeksiyonlarına göre, yaşlı nüfus oranının 2023 y1lında \%10,2; 2030 y1lında $\% 12,9 ; 2040$ y1lında $\% 16,3$; 2060 y1lında \%22,6 ve 2080 y1lında $\% 25,6$ olacağ 1 öngörülmektedir (1).

Yaşlı nüfusun fazla olduğu toplumlarda, gerekli önlemleri almak adına ileri yaş hastalıklarına yönelik hem bakım ve tedavi programları hem de korunma yöntemleri geliştirilmektedir. Toplumun yaş dağılımında görülen değişiklikler, karşılaşılan sağlık sorunlarını ve sunulması gereken sağlık hizmetlerini etkilemektedir. Bu konudaki kaygılar politikacıları da endişelendirmekte ve bu konu ilgilerini çekmektedir. Geliştirilen sağlık politikaları sayesinde yaşl1lara verilecek koruyucu ve tedavi edici sağlık hizmetleri ile yaşlıların bağımsız yaşaması sağlanmaya çalışılmaktadır. Yaşlıların yaşamlarının niceliği kadar niteliği de önemli olmaktadır. Uzun yaşamanın yanında nitelikli yaşama ve bunu belirleyen faktörler de önemli hale gelmiştir.

Yaşlı nüfustaki artışla beraber kronik hastalıkların görülme sıklığı ve bu bireylerin bağımlılığı artmaktadır.
$\mathrm{Bu}$ dönemde bireyler günlük yaşam aktivitelerini devam ettirebilmek için bir başkasının yardımına gerek duyabilmektedirler. Bakıma ihtiyacı olan yaşlıların kurumlarda ya da ev ortamlarında bakılmaları gerekmektedir $(2,3)$. Ancak kurumlarda sunulan bakım hizmetlerinin maliyetleri yüksek olabilmekte ve yaşlı bireyi toplumsal yaşamdan ayırabildiğinden verilecek bu hizmetlerin olabildiğince kişinin kendi yaşam alanından kopmadan gerekli destek hizmetlerinin sağlanması gerekmektedir. Aile bireyleri ve sosyal hizmet uzmanları bu aşamada önem arz eder. Ancak endüstrileşme ve şehirleşmenin getirdikleri ile aile yapısı küçülmekte ve yaşlı bireylerin bakımı güçleşmektedir. $\mathrm{Bu}$ durumda yaşlıya sunulacak hizmetin önemi ortaya çıkmaktadır (4).

Demografik profilde meydana gelen değişikliklere hem sağlık hizmeti sunanlar hem de sağlık politikacıları kayıtsız kalmayıp toplumun önceliklerini belirleyecek, bu konuya yönelik politika ve stratejiler geliştirerek olası sorunların önüne geçebileceklerdir.

\section{Yaşlılık ve Bu Dönemdeki Sağlık Sorunları}

Yaşlanma, bireysel bir değişim olarak kişinin hem fiziksel hem de ruhsal açıdan gerilemesidir. Yaşlanma bireyseldir, fakat toplumsal değerler de yaşliya ve yaşlilığa verilen değeri ve yeri belirler. Bu nedenle yaşlılık sadece biyolojik bir olay olmayıp, aynı zamanda toplumsal ve kültürel bir olaydır (5). Yaşlanma, morfolojik, fizyolojik, biyokimyasal ve mental özelliklerdeki gerilemenin birikimi ile ortaya çıkan karmaşık bir olaydır.

Yaşlanma ile birlikte sistemler üzerinde birçok fizyolojik değişiklik olmaktadır. Böbrek kitlesinin ve fonksiyonunun azaldığı görülür. Böbrek kan akımında ve mesane kapasitesinde azalma meydana gelir. İdrar kaçırma önemli bir sorun olarak yaşlı bireyin karşısına çıkabilir. Gastrointestinal sistemde hareket, salg1 ve emilim kapasitesinde azalma görülür. $\mathrm{Bu}$ durum ağız sağlığını da olumsuz etkiler. Dişlerin kaybı ve çiğneme fonksiyonunda azalma meydana gelebilir. Yağsız vücut kitlesi azalırken, yağ kitlesinde artış olur. Kardiyovasküler sistemdeki değişiklikler kalp kitlesinde, büyük damarların sertleşmesinde, sistolik kan basıncında artışla kendini gösterir. Felç ve demans gelişimine sık rastlanır. Solunum sisteminde sorunlar yaşanabilir ve bu durumda kanın oksijenlenmesinde azalma görülür. Tırnak büyüme hızı ve deri pigment hücreleri azalır. Kas iskelet sisteminde, kemik kitlesi ve kuvvetinde azalma, 
boyda kısalma görülür. Kas kitlesi azalır, kaslar daha çabuk yorulur. Reflekslerde yavaşlama ve bellek kaybı yaşanabilir.

Yaşl1lık döneminde sıklıkla görülen koroner arter hastalığı, kanserler, beyin-damar hastalıkları ülkemizde toplam ölümlerin \%51,3'üne neden olmaktadır. Ülkemizde 1,2 milyon koroner kalp hastasının olduğu ve bu hastaların 130000'inin öldüğü tahmin edilmektedir (6). Ayrıca yaşla paralel olarak dejeneratif hastalıklardaki görülme sıklığının artması hastaları düşme ve kazalara bağlı problemler nedeniyle daha fazla tedaviye ve bakıma ihtiyaç duyar hale getirmektedir.

\section{Yaşlılara Yönelik Sağlık ve Bakım Hizmetleri}

Toplam nüfus içindeki yaşlı sayısının artmış olması yaşlılara verilecek sağlık hizmetlerini gündeme getirmektedir. Dünya nüfusunun demografik yapısının değişmesi ile sağlık hizmetlerinde zorluklar yaşanmakta, emeklilik yaşına ulaşıldığında sağlık hizmetlerine olan ihtiyaçlar artmakta ve bu artış 75 yaş üzerinde hızlı bir ivme kazanmaktadır (7). Bu durumda yaşlılara sunulacak sağlık ve bakım hizmetleri önemli olmaktadır. Yaşlılıkta sağlık hizmeti sunumu toplumun tam katılımı ile sağlanmalı, hem yaşlı birey hem de aileleri için ulaşılır, uygulanabilir, karşılanabilir bir maliyete sahip hizmetlerden oluşmalıdır. Yaşlılara sunulan sağlık hizmetlerini ve bu hizmetlerin verildiği kurumları, işleyişleri ve özelliklerini şu başlıklar halinde inceleyebiliriz.

Geriatri Hastaneleri: Yaşlı bireylere bakım, tedavi ve rehabilitasyon hizmetlerinin verildiği yaşlı bakım üniteleridir. Geriatri hastanelerinde görev alan profesyoneller; doktor, hemşire, farmakolog, sosyal çalışmacı, fiziksel rehabilitasyon terapistleri ve ruh sağlığ 1 uzmanlarıdır (8).

Subakut Bakım Üniteleri: Bazı yaşlı bakım evlerinde ayrı bir birim içinde sunulabilir hizmetlerdir. Genelde tıbbi ve hemşirelik bakımına kısa süreli ihtiyaç duyan yaşlı bireyler bu ünitelerde tutulur. Burada bireyler rehabilitasyon hizmeti de alır ve kısa sürede hastanın evine ya da yaşlı bakım evine dönmesi amaçlanır (9).

Son Dönem Hastaneleri (Hospice Care): Terminal dönemde olan hastalara ve onların ailelerine fiziksel, sosyal ve ruhsal bakım hizmetinin verildiği ünitelerdir. Ölümü beklenen bireylere rahat, huzurlu ve onurlu bir ölüm sağlamak üzere yapılandırılmışlardır. Ağrı kontrolü, semptomların yönetimi ve manevi destek sağlar. Ailelere de ölüm ve süreci hakkında eğitim ve destek sağlanır (10).

Gündüz Hastaneleri: Yaşlı bireylere gündüz bakım hizmeti sunan merkezlerdir. Çoğunlukla mental ve fiziksel yetersizliği olan hastalara tıbbi bakım hizmeti sağlanır. Gün boyunca evde olmayan ailelerin evde yalnız kalamayacak durumda olan yaşlılarına verilen hizmetlerdir. Günlük bakım alan yaşlılar akşam evlerine dönerler. Bu hastanelerde yaşlılara bakım, tedavi ve koruyucu hizmetlerin yanında rehabilitasyon ve sosyal hizmet desteği de sağlanmaktadır (11).

Bakım Evleri (Nursing Home): Yaşlıların uzun süreli hizmet aldıkları bakım üniteleridir. Yaşlılara sürekli kişisel ve sosyal bakım hizmeti verilir ve burada ölene kadar kalabilirler. Bu hizmeti alan yaşlılar genellikle demansı (bunama) olan, işitme sorunu yaşayan ve eşi olmayan yaşlılardır. Çoğu yaşam aktivitelerini gerçekleştirmek için farklı seviyelerde yardıma ihtiyaç duyarlar. Bu birimlerde yaşlının temel bakım ihtiyacını sağlayan profesyoneller gerontoloji uzmanları, doktorlar ve hemşirelerdir (12).

Evde Bakım Hizmetleri: Günlük hayatlarında hemşirelik bakımına gereksinimi olan yaşlı kişilere kurum bakım ihtiyacını önlemek veya geciktirmek için profesyonel halk sağlığı hemşireleri tarafindan bireyin evinde sunulan hizmetlerdir. Evde verilen hizmetler çoğunlukla hemşirelik becerisi, fiziksel terapi, meşguliyet terapisi, konuşma terapisi, sosyal çalışma, beslenme danışmanlığı ve bazı tıbbi bakım hizmetlerinden oluşur. Bu durumda evde bakım hizmetlerinin multi-disipliner bir ekip çalışması gerektirdiği anlaşılmaktadır. Bu hizmetle bireyler bulundukları ortamdan kopmadan, desteklenerek ve sosyal yaşama ayak uydurabilmeleri sağlanmaktadır. Böylece hem yaşlı bireye hem de ailesine sunulan psikososyal, fizyolojik ve tıbbi destek hizmetleri ile kişilerin yaşlılık dönemlerini mutlu ve huzurlu bir şekilde sürdürüp toplumla bütünleşmelerinin sağlandığ sunulmaktadır (13).

Yaşlılara Sunulan Sosyal Hizmetler: Bu hizmetleri sunan yaşlı merkezleri, 1940'larda yaşlıların sosyal ve eğlence ihtiyaçlarını karşılamak için kurulmuş çok amaçlı merkezlerdir. Bu kapsamda sunulan hizmetlerin bir kısmı; beslenme ve yemek hazırlama hizmetleri, ziyaret hizmetleri, telefon hizmetleri, danışmanlık hizmetleri, günlük ev işleri hizmetleri, taşıma ve refakat hizmetleri, yaşlı kulüpleri, yaşlı sığınma evleri, yaşlı apartman hizmetleri, pansiyon hizmetleridir $(14,15)$. 


\section{Ülke Örnekleri ile Yaşlı Bakım Hizmetleri}

Amerika Birleşik Devletleri: ABD' de yaşlı nüfusun artması ile 1970'li yılların sonunda "yaşlı nüfusun desteklenmesinde ekonominin yeterliliği” kavramı üzerinde durulmuştur. Sosyal güvenlik fonlarında yaşanan krizler, işsizlik ve enflasyon oranındaki artış nedeni ile bu kavrama önem vermişlerdir (16).

ABD'deki 65 yaş ve üzeri nüfusun 2050'de \%21'e ulaşacağı ön görülmektedir. 2002 bütçe ofisine göre bunun sebebi sadece yaşlı nüfusun artması değil aynı zamanda uzun yaşam beklentisin artmasıdır. Hastane dışı sağlık bakım teknolojisindeki ilerlemeler hastane dışı evde bakım veya kurum bakımının talebinde artsşa neden olmuştur (17). Hastane temelli ilk evde bakım programı 1947 yılında New York, Bronx'un Montefiore Hastanesinde başlamıştır. Bu programla evde bakım çok disiplinli olarak sunulan bir sağlık hizmeti alternatifi halini almıştır.

ABD'de hizmetlerin verildiği bazı kurumlar: Bağımsız emeklilik evleri (independent retirement housing), toparlayıcı evler (congregate housing), kişisel bakım evleri (personal care housing), özel bakım evleri (skilled nursing homes), yaşam boyu bakım topluluğudur (life care community) (18).

Yaşlılar için üretilen programlar: Koruyucu büyükanne ve büyükbabalık programı, yaşlıya arkadaşlık programı (senior companion), emekli ve yaşlılara gönüllü hizmetler programıdır (retired senior voluntary program) (19).

İngiltere: İngiltere'de de tüm dünyada olduğu gibi yaşl1 nüfus oranının tüm nüfus içindeki payının arttığ 1 ve 2025 vizyonuna göre artacağ 1 ön görülmektedir. Bu durumda yaşlı bakım hizmetlerine önem vermeleri gerektiğinden kapsamlı çalışmalar yapılmaktadır.

Sosyal hizmetler kapsamındaki bakım hizmetlerine önem verilmiştir. Evde bakım İngiltere'de görülen hizmetlerden birisidir. Hasta bireylerden sağlık otoriteleri sorumlu olmuş, bakıma ihtiyaç duyan ve dikkat sorunu nedeniyle ayakta duramayanların sorumluluğunu ise yerel yönetimler almıştır. Karma bir bakım modelinin varlığı göze çarpmaktadır. Bir taraftan sağlık kurumu veya yerel idareleri bakım hizmeti sunarken, diğer taraftan ailelerin de bu bakıma dahil olması beklenmektedir (20).

İngiltere'de yaşlılar için kurulmuş ve "yaşlılar köyü" olarak adlandırılan özel bölgeler bulunmaktadır. Burada bulunan yaşlılar sağlık profesyonelleri ile daha yakın ilişki içindedir. Ayrıca kendilerine ait kararları kendileri alabilecek durumdadırlar (21). Yaşlılar ulusal sağlık hizmeti kapsamında korunurlar. Ev hemşirelik hizmetleri bölgesel sağlık birimleri tarafından sağlanır. Kurum bakımını yerel hükümet (belediyeler) sunar. Ayrıca yaşlıların ev dışında yardım alabilecekleri gündüz bakım evleri/gündüz hastaneleri, basit tıbbi bakım, ilaç yardımı ve fizyoterapi hizmetleri verilmektedir (22).

Hollanda: Birçok Avrupa ülkesi gibi yaşlanan bir toplumdur. $\mathrm{Bu}$ durumun ekonomideki olumsuz yansımalarını görüp 2007 yılında reformlara başlamıştır. Böylece önemli değişikliklere gidilmiş, kurum bakımından evde bakım sistemine geçilmiş, evde bakım hizmetleri belediyelere devredilmiştir (23).

Hollanda hükümet yetkilileri, yaşl1ların kendi evlerinde mümkün olduğunca uzun süre, gerekiyorsa bazı hizmetler ile desteklenerek yaşayabilmelerini amaçlamıştır. Evde bakım hizmeti kişisel bakım ve hemşirelik bakımı ile rehberlik hizmetlerini içermektedir. Yaşlılar eve yemek servisi hizmeti ile desteklenir. Gündüzlü hizmet veren yaşlı dayanışma merkezleri vardır. Uzun süre evinde kalamayan yaşlılar yaşlı apartmanı, huzurevi veya bakımevlerine giderler (23).

Hollanda'da Yaşılırın Faydalandığı Hizmetler ve Kuruluşlar: Semt yaşlılar merkezi, evde yaşlı bakımı hizmeti, evlere yemek servisi hizmeti, yaşlı apartmanı-service home (de-nieuwe plantage, hoppesteyn), huzurevi-elderly home (maashegge), bakımevi-nursing home, yaşlı dayanışma merkezi-day care center - cypres, yaşlı dayanışma merkezi (swon projesi), geriatrik hizmetlerdir (24).

\section{Türkiye'de Yaşlı Bakım Hizmetleri}

Yaşlanma konusu gelişmiş ülkelerin sorunu olduğu kadar gelişmekte olan ülkeler için de bir sorun olup önemle üzerinde durulmalıdır. Araştırma sonuçlarına göre ülkemiz yeni bir demografik yapıya geçmektedir. Çocuk ve genç nüfusun zaman içerisinde azalması ve yaşlı nüfusun toplam nüfus içerisindeki payının artması öngörülmektedir (Tablo 1). Gelişmiş ülkelerde nüfusun yaşlanmasının sosyoekonomik yapıya olan etkileri üzerine değerlendirmeler yapılmakta ve yaşlı nüfusun sosyal hayatlarından ayrılmadan yaşamlarını devam ettirmelerini sağlayacak çalışmalar öne geçmektedir. Ülkemiz için demografik değişimlerin yansımaları iyi değerlendirilmeli, bu konunun ülkemiz için bir soruna dönüşmeden çözümlenmesi gerekmektedir (5). Ülkemizde de yaşlı nüfus sayısının hem sayısal hem oransal 
Tablo 2: Kamu, özel, belediye, dernek, vakıf ve azınlıklara ait huzurevleri sayısı, kapasiteleri ve bakılan yaşlı sayısı (27)

bakıldığında uluslararası sınıflandırmalar kapsamında yaşlı toplumlar sınıfına girmiştir. Yaşlı nüfus artışının devam edeceği öngörülüp bu durum yaşlılara sunulacak hizmetlere önem verme gerekliliğini göstermektedir (25).

Tablo 1: Cinsiyete göre yaşlı nüfus ve yaşlı nüfusun toplam nüfus içindeki oranı, 1935-2080 (26)

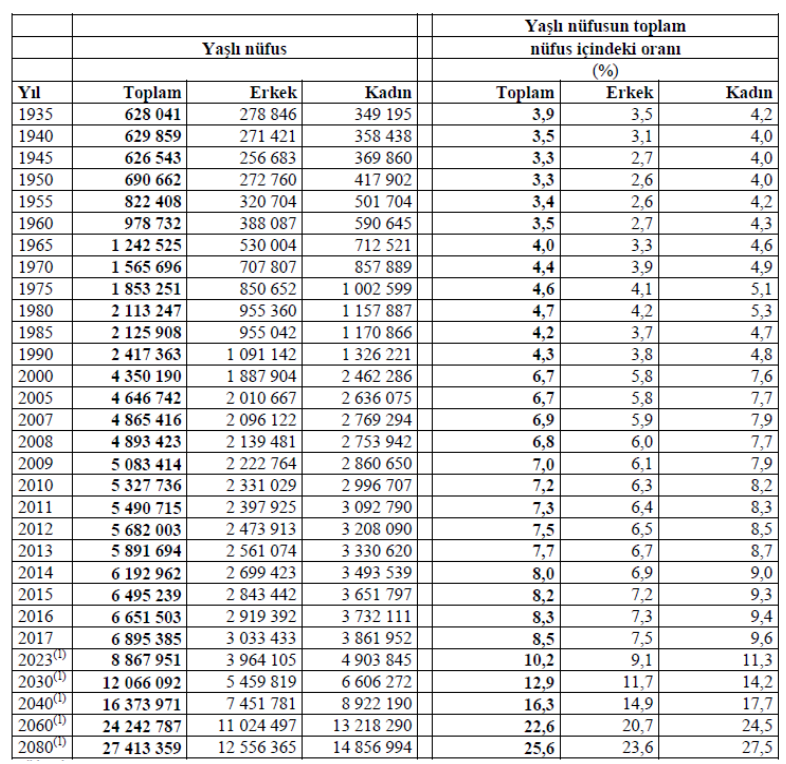

TÜIK, İstatistiklerle Yaşlılar, 2017

Ülkemizde yaşlı bireylere huzur evleri, yaşlı bakım merkezleri, yaşlı dayanışma merkezleri, yaşlı bakım ve rehabilitasyon merkezlerinde hizmet sunulmaktadır. Kızılay, Bağ-Kur, Sosyal Hizmetler ve Çocuk Esirgeme Kurumu (SHÇEK) yaşlılarla ilgilenen önemli kurumlardandır.

Sosyal güvenlik hizmetleri; Sosyal Güvenlik Kurumu, Banka ve Sigorta Şirketleri Sandıkları gibi kurumlar tarafindan verilmektedir (3).

Sosyal Hizmetler; kurum bakım hizmetleri (huzur evleri), evde bakım hizmetleri, yaşlı kulüpleri, yaşlı dayanışıma merkezleri, yaşlı bakım ve rehabilitasyon hizmetleri olarak sunulmaktadır.

Huzurevleri: Ekonomik gücü yeterli olmayan, bakımından sorumlu kimsesi bulunmayan, kendisine bakacak gücü olmayan yaşlılara ücretsiz, ekonomik gücü yerinde olan fakat sosyal yoksunluk içinde bulunan yaşlı bireylere ücretli olarak hizmet sunulur. Ülkemizde toplam 392 huzurevi ile yaşlı bireylere hizmet sunulmaktadır (Tablo 2). Burada yaşlılara barınma, sağlık, psikolojik destek, beslenme-temizlik hizmetleri, boş zamanını değerlendirme hizmeti ve sosyal faaliyetler kazandırılmaktadır.

\begin{tabular}{|c|c|c|c|}
\hline $\begin{array}{l}\text { YATILI BAKIM HUZUREVLERÍ } \\
2018 \text { Nisan }\end{array}$ & $\begin{array}{l}\text { HUZUREVI } \\
\text { SAYISI }\end{array}$ & KAPASITE & $\begin{array}{l}\text { BAKILAN } \\
\text { Kiși SAYISI }\end{array}$ \\
\hline $\begin{array}{l}\text { BAKANLIGIMIZA BAGLI } \\
\text { HUZUREVLERI }\end{array}$ & 145 & 14.837 & 13.791 \\
\hline YAȘLIYASAMIEVI & 47 & 179 & 164 \\
\hline $\begin{array}{l}\text { DIGGER BAKANLIKLARA BAGLI } \\
\text { HUZUREVLERI }\end{array}$ & 2 & 570 & 566 \\
\hline BELEDIYYELERE AITT HUZUREVLERI & 22 & 3.402 & 2.381 \\
\hline $\begin{array}{l}\text { DERNEK VE VAKIFLARA AIT } \\
\text { HUZUREVLERI }\end{array}$ & 29 & 2.454 & 1.717 \\
\hline AZINLIKLARA AITT HUZUREVLERİ & 5 & 508 & 355 \\
\hline ÖZEL HUZUREVLERI & 189 & 10.559 & 7.128 \\
\hline TOPLAM & 392 & 32.509 & 26.102 \\
\hline
\end{tabular}

Evde Bakım Hizmetleri: Kurumbakımının pahalılması ve yaşlı bireyi yaşadığı sosyal çevreden uzaklaştırması gibi nedenlerle evde bakım hizmetlerine önem verilmektedir. Evde bakım hizmetinden faydalanabilecek gruplar; hastaneden taburcu olduktan sonra tedavisinin devam etmesi gereken hastalar, kronik hastalıkları veya özürlü olması nedeniyle evden çıkamayan bireyler, kendi bakımını yapamayan ya da evinde bakımını yapacak kimsesi olmayan, zihinsel rahatsızlıkları olan, huzurevlerine şartları uymadığı için kabul edilemeyen, terminal dönemde olup bu dönemini evinde huzurlu bir şekilde geçirmesi istenen ya da sadece aralıklı bakım ihtiyaç duyan kişilerdir. Evde bakım hizmetlerini tüm yaş grupları alabilmekle birlikte, daha çok 65 yaş ve üzeri yaşlarda olan kişiler almaktadırlar (28).

Yaşlı Kulüpleri ve Yaşıı Danışma Merkezleri: Ailesi ile birlikte veya yalnız yaşayan 60 ve daha yukarı yaştaki kişilere sosyal, psikolojik ve sağlık ihtiyaçları için destek hizmetler veren gündüzlü kuruluşlardır. Üye olan yaşlılar sohbet ve eğlence toplantılarına katılabilir, psikolojik danışmanlık hizmeti, çeşitli konularda rehberlik hizmeti alabilir, refakatçi temini, el becerilerini geliştirecek çeşitli aktiviteler ve temel sağlık yardımları gibi hizmetlerden de faydalanabilirler (3).

Yaşlı Dayanışma Merkezleri: Yatılı kurum bakımı ihtiyacı olmayan, evlerinde yalnız ya da ailesi ile yaşayan yaşlıların sosyal ve psikolojik ihtiyaçlarını karşılamak için açılmış gündüzlü kuruluşlardır. Bu merkezlerde yaşlı bireylere zamanlarını değerlendirmelerini sağlamak, hayat koşullarını iyileştirmek, rehberlik ve mesleki danışmanlık sunmak, sosyal ilişkilerini ve aktivitelerini artırmak amaçlanmıştır (21).

Yaşlı Bakım ve Rehabilitasyon Merkezleri: İşlerini yapabilmek için bir başkasının yardımına ihtiyaç duyan yaşlıların hizmet aldığı merkezlerdir. Ruh sağlığ yerinde olan, bulaşıcı hastalığı olmayan, yatağa bağımlı, bedensel, görme-işitme özürlü olan ve demanslı yaşlı bireyler bu 
merkezlere kabul edilmektedirler. Maddi gücü yeterli olmayanların tedavileri devlet tarafindan ücretsiz yapılıp, ilaç, protez gibi ihtiyaçları da parasız karşılanmaktadır (21).

\section{SONUÇ}

$\mathrm{Bu}$ çalışmada yaşlılık döneminde yaşanabilecek sağlık sorunlarına değinilmekte, ülke örnekleri ile yaşlı bakım hizmetlerinin özelliklerinden bahsedilmektedir. Türkiye'deki yaşlı bakım hizmetleri hakkında bilgi verilerek konunun önemine dikkat çekilmesi ve ülkemizde yapılabilecekler hakkında fikir oluşturulması amaçlanmıştır.

Türkiye'nin nüfus yapısını incelediğimizde yaşlanma sürecine girdiğini görmekteyiz. Dolayısı ile yaşlı sağlığ planlaması artık ülkemiz için de zorunlu bir ihtiyaçtır. Ülkemizde resmi ve özel kurumlar tarafından yaşlı bakım hizmeti verilmekle birlikte bu oranın düşük olduğu, yaşlı bireylerin çoğunlukla kendi evinde yaşamayı tercih ettiği gözlenir. İhtiyaç sahibi olan yaşlı bireyler kendi sosyal alanlarından, günlük aktivitelerinden, yakın akraba ve arkadaş çevresinden ayrılmadan sağlıklı bir hayat sürdürmesi için desteklenmeli, yaşam kalitesini artırmak adına evde bakım uygulamaları yaygınlaştırılmalı, bakım ve rehabilitasyon hizmetleri olabildiğince yaşlı bireyin evinde sunulmaya çalışılmalıdır. Ayrıca yemek, temizlik, kişisel bakım gibi hizmetlerin ve takip devamlılığının sağlanması, bunlar için de sosyal düzenlemelerin yapılması gereklidir. Yaşlı bireyin bakımından sorumlu olan aile bireyleri de psikolojik, sosyal ve ekonomik açıdan desteklenmelidir. Yaşlı bakım hizmetlerine yönelik uygun politikaların geliştirilmesi, etkinlik ve verimliliğin sağlanması gerekmektedir.

\section{KAYNAKLAR}

1. TÜİK, Türkiye İstatistik Kurumu, İstatistiklerle Yaşl1lar, 2017.www.tuik.gov.tr/PdfGetir.do?id=27595 [Erişim Tarihi:24.05.2018]

2. Akın B, Seviğ Ü, Karataş N. Türkiye'de Gerontoloji Hemşireliği Eğitimi (1): Bir Sertifika Programı Geliştirme Çalışması Programın Dayandığı Temeller, Deneyimler ve Eğitim Programı Önerisi. Cumhuriyet Üniversitesi Hemşirelik Yüksek Okulu Dergisi, 2001; 5: 33-39.

3. Altay B, Emiroğlu O N, Yaşlılık Hizmetleri Ondokuz Mayıs Üniversitesi Tıp Dergisi, 2005; 22(4): 165-170.

4. Akgün S. Dünyada ve Türkiye'de Yaşlı Nüfus Eğilimi, Sorunları ve İyileşme Önerileri. Türk Geriatri Dergisi 2004; 7: $105-110$.

5. DPT, 2007; 10.
6. Turaman C, Yaşı Sağlığı Hizmetlerinin Birinci Basamakta Planlanmas1, Geriatri 2014; (1): 22-27.

7. Büken N. Ö, Büken E, Yaşlanma Olgusu ve Tıp Etiği, Geriatri, Turkish Journal of Geriatrics, 2003; 6 (2): 75-79.

8. Factor A, Parker M. Managing Chronic Diseases. 2010.

9. Okumuş H, III. Basamak Sağlı Hizmetlerinde Yaşlı Bakımı, I. Ulusal Geriatri Kongresi Bildiri Kitab1, 2002; 30 Ekim - 3 Kasım.

10. https://eldercare.acl.gov/Public/Resources/Factsheets/ Hospice Care.aspx [Erișim Tarihi: 05.06.2018]

11. http://elderlyservices.org/ [Erişim Tarihi: 05.06.2018]

12. http//www.ncbi.nlm.nih.gov/entrez/query. [Erişim Tarihi: 05.06.2018]

13. Altuntaş M, Yılmazer TT, Güçlü Y A, Öngel K, Evde Sağlık Hizmeti ve Günümüzdeki Uygulama Şekilleri, Tepecik Eğitim Hastanesi. Dergisi. 2010; 20 (3): 153-8.

14. Altay B, Emiroğlu ON, Yaşlılık Hizmetleri, Ondokuz Mayıs Üniversitesi Tıp Dergisi, 2005; 22(4): 165-170

15. Fletcher K, Westley CJ. Elderly Health. in: Stanhope M, Lancaster J (eds.) Community Public Health Nursing, 4th ed. Printed in The United States of America, 2000; 597-613

16. Kuzgun İ K, Nüfusun Yaşlanmasının İş Gücü Arzına Etkisi. Geriatri, 2002; 5 (1):38.

17. https://geriatrics.ucsf.edu/care/over60.html [Erişim Tarihi: 05.06.2018]

18. Güngör, C. Yaşlı Bakımevleri ve Tasarım Prensipleri Üzerine Bir İnceleme, Gazi Üniversitesi Fen Bilimleri Enstitüsü, Yüksek Lisans Tezi. 2002; 30-31.

19. Biçer H. Sosyal Sorunlar Çerçevesinde Yaşlilar, Ankara Üniversitesi Sosyal Bilimler Enstitüsü Çalışma Ekonomisi ve Endüstriyel İlişkileri Anabilim Dalı, Yüksek Lisans Tezi. 2002; (102-103-106-107).

20. Sundström, G. ve Johansson L.. The Changing Balance of Government and Family in Care for the Elderly in Sweden and Other European Countries. Australasian Journal on Ageing, 2005; 24 (5-11).

21. Altan Ö, Şişman Y, Yaşlılara Yönelik Sosyal Politikalar Kamu-İş. 2003; 7(2).

22. Kural F. Türkiye'de Müșteri İlișkilerinin Huzurevi İşletmeciliğine Etkisi ve Huzurevlerine Dair Öneriler, Yüksek Lisans Tezi, İstanbul. 2001; 6, 18-31.

23. Sevim K, Hollanda'da Yaşlı Bakım Hizmetleri, Sosyal Çalışma Dergisi, 2017; 1(1), 55-63.

24. Sezgin G, Counc1l Of International Fellowship Cif Hollanda Mesleki ve Kültürel Değişim Programı, Yaşlılık ve Özürlülük Alanı, 2001.

25. Karakuş B, Türkiye'de Yaşlilara Yönelik Kurumsal Bakım İhtiyacı, Tespit ve Öneriler, Engelli ve Yaşlı Hizmetleri Genel Müdürlüğü, Ankara, 2015.

26. TÜİK, Genel Nüfus Sayımları, 1935-1990, TÜİ, Nüfus Tahminleri, 2000-2007, TÜİK, Adrese Dayalı Nüfus Kayıt Sistemi, 2008-2017, TÜiK, Nüfus Projeksiyonları, 20232080.

27. Engelli ve Yaşlı Bakım Hizmetleri Genel Müdürlüğü.

28. Pınar R, Türkiye'de Evde Bakımda Mevcut Durum, 2010.http:// www.akademikgeriatri.org/files/Akademik_Geriatri_2010/ Konusma_Metinleri/16.pdf) [Erişim Tarihi:15.05.2019] 